JPEKA Vol. 2 No. 1 Mei 2018

Hal. 1 - 10

\title{
Analisis Faktor-Faktor Yang Mempengaruhi Keputusan Pemilihan Universitas Pada Siswa Kelas XII SMA Negeri 22 Surabaya
}

\author{
Anggraini Puspitasari ${ }^{1}$, Finisica Dwijayati Patrikha ${ }^{2}$ \\ ${ }^{1}$ Program Studi Pendidikan Tata Niaga, Fakultas Ekonomi, Universitas Negeri Surabaya, \\ anggrainipuspitasari14@gmail.com \\ ${ }^{2}$ Program Studi Pendidikan Tata Niaga, Fakultas Ekonomi, Universitas Negeri Surabaya, \\ finisicapatrikha@unesa.ac.id
}

\begin{abstract}
Abstrak
Pendidikan merupakan prioritas terpenting bagi sebagian besar masyarakat. Hal ini terjadi karena masyarakat mempunyai harapan dapat melanjutkan dan menyelesaikan pendidikannya hingga ke jenjang yang lebih tinggi. Jenjang yang lebih tinggi tersebut yaitu kuliah, dimana siswa akan dihadapkan pada pemilihan berbagai jenjang pendidikan mulai dari Diploma (DI, DII, dan DIII) maupun Sarjana (S1). Tujuan penelitian ini adalah untuk mengetahui faktorfaktor yang mempengaruhi keputusan pemilihan Universitas pada siswa kelas XII SMA Negeri 22 Surabaya. Penelitian ini termasuk dalam jenis pendekatan kuantitatif dan bersifat confirmatori. Teknik sampel menggunakan proportional random sampling, dengan sampel 190 responden dan populasi 362. Hasil penelitian ini adalah faktor yang mempengaruhi keputusan pemilihan Universitas pada siswa kelas XII SMA Negeri 22 Surabaya yaitu kelompok referensi, citra lembaga, motivasi, keluarga, lokasi, dan harga. Faktor yang mempunyai pengaruh paling dominan adalah kelompok referensi, citra lembaga, motivasi, keluarga, lokasi, dan harga.
\end{abstract}

Kata Kunci: Analisis Faktor, Keputusan Pemilihan, Kelompok Referensi.

\begin{abstract}
Education is the most important priorities for the most society. This happens because the society have expectation to continue and finish education to the higher level. The higher level is studying in University, where the students will faced to select various levels of education such as Diploma (DI,DII and DIII) and Bachelor (S1). The aim of research is to know the factors which influence to student decisions in SMA Negeri 22 Surabbaya to select Universities. The research type was a quantitative approach, wich had confirmatory characteristic. The sampling technique was proportional random sampling, with the sample of the 190 respondents and 362 populations. The result of this research were of factor that related to student in SMA Negeri 22 Surabaya to select Universities, reference group, barand image, motivation, family, location, and price. And the strongest relation which influenced the University election decisions of the XII grade students SMA Negeri 22 Surabaya was reference group,brand image,motivation,family,location, and price.
\end{abstract}

Keywords: Factor Analysis, Selection Decision, Reference Group.

\section{PENDAHULUAN}

"Pendidikan merupakan prioritas yang paling penting untuk masyarakat. Hal ini terjadi 
karena masyarakat mempunyai harapan dapat melanjutkan dan menyelesaikan pendidikannya hingga ke jenjang yang lebih tinggi. Jenjang yang lebih tinggi tersebut yaitu kuliah, siswa dihadapkan pemilihan berbagai jenjang pendidikan mulai dari Diploma (DI, DII, dan DIII) maupun Sarjana (S1). Pada Undang-Undang Nomor 20 Tahun 2003 mengenai Sistem Pendidikan Nasional menyatakan perguruan tinggi berbentuk universitas, politeknik, sekolah tinggi, institut, dan akademi."

Penelitian Artini (2014) menjelaskan bahwa harga dan keluarga mempengaruhi keputusan mahasiswa dalam memiih jurusan di Fakultas Ekonomi dan Bisnis Undisksha sebagai tempat kuliah sehingga penelitian ini menjadi bahan referensi dalam penelitian peneliti.

Persaingan masuk kuliah terjadi di SMA Negeri 22 Surabaya. Siswa SMA Negeri 22 Surabaya melanjutkan kuliah sehingga penelitian dapat dilakukan di SMA Negeri 22 Surabaya yang respondennya ditunjukkan siswa kelas XII. SMA Negeri 22 Surabaya yang mempunyai 3 jurusan yaitu jurusan IPA, jurusan IPS dan jurusan Bahasa. Jurusan IPA mempunyai 5 kelas, jurusan IPS mempunyai 4 kelas dan jurusan Bahasa memiliki 1 kelas. Pemilihan responden kelas XII ada berbagai hal alasan diantaranya mereka yang akan lulus dari SMA dan yang kedua mereka melanjutkan kuliah. Lokasi penelitian ini berada di Jl. Balas Klumprik No.22, Surabaya tepatnya di SMA Negeri 22 Surabaya dengan profil akreditasi A.

"Data diperoleh dari observasi menunjukkan bahwa siswa yang diterima di perguruan tinggi negeri maupun swasta mengalami naik turun. Siswa kelas XII tahun pelajaran 2014/2015 sebanyak 297 siswa diterima di universitas negeri dan 103 siswa diterima di universitas swasta. Sedangkan siswa kelas XII tahun pelajaran 2015/2016 329 siswa diterima di universitas negeri dan 79 siswa diterima di universitas swasta. Siswa kelas XII tahun pelajaran 2016/2017 sebanyak 275 siswa diterima di universitas negeri dan 115 siswa diterima di universitas swasta."

Kottler (2008:235) menyatakan bahwa keputusan pembelian merupakan tahap proses pengambilan keputusan, yaitu konsumen membeli produk. Pengambilan keputusan merupakan kegiatan individu secara langsung terlibat dalam mendapatkan dan mempergunakan barang yang ditawarkan oleh produsen. Dalam keputusan pembelian, konsumen harus melalui lima tahapan proses pengambilan keputusan yaitu: (1) pengenalan masalah, (2) pencarian informasi, (3) evaluasi aternatif, (4) keputusan pembelian, (5) perilaku pasca pembelian. Hal ini terjadi dalam memilih lembaga pendidikan yang sesuai dengan kriteria konsumen (siswa) dimana beberapa faktor menjadi pertimbangan dalam mempengaruhi keputusan memilih lembaga pendidikan khususnya universitas.

"Dalam menarik minat siswa, Universitas memahami faktor-faktor yang menarik siswa dalam pemilihan Universitas. Kelompok referensi, keluarga, motivasi, lokasi, harga/biaya, dan citra lembaga merupakan suatu pertimbangan dalam menentukan faktor untuk objek penelitian di SMA Negeri 22 Surabaya.“

Berdasar uraian tersebut penulis melakukan penelitian dengan judul Analisis Faktor-Faktor Yang Mempengaruhi Keputusan Pemilihan Universitas Pada Siswa Kelas XII SMA Negeri 22 Surabaya. Kemudian dari latar belakang tersebut, maka dapat dirumuskan sebagai berikut: (1) Faktor apa yang mempengaruhi pemilihan Universitas pada siswa kelas XII SMA Negeri 22 Surabaya?, (2) Manakah diantara faktor tersebut yang mempunyai pengaruh paling dominan yang mempengaruhi pemilihan Universitas pada siswa kelas XII SMA Negeri 22 Surabaya?.

Menurut Loundon dan Bitta mendefinisikan bahwa "Perilaku konsumen adalah proses dalam pengambilan keputusan yang mensyaratkan aktivitas individu untuk mengevaluasi, 
mencari, menggunakan barang dan jasa." Menurut Engel et al mendefinisikan bahwa "Perilaku konsumen adalah tindakan langsung agar dapat mengkonsumsi, dan menghabiskan produk dan jasa, termasuk dalam proses keputusan yang mengikuti tindakan tersebut." Memahami perilaku konsumen merupakan sesuatu yang sangat kompleks, kompleksitas permasalahan disebabkan banyaknya variabel yang saling mempengaruhi untuk saling berinteraksi. Agar dapat memahami perilaku konsumen maka diperlukan model perilaku konsumen.

Menurut Kotler dan Keller (2009) ada empat faktor utama mempengaruhi perilaku konsumen antara lain: (1) Faktor Budaya, (2) Faktor Sosial, (3) Faktor Pribadi, (4) Faktor Psikologis.selanjutnya, menurut Henry Assael dalam Amirullah (2002) ada tiga faktor mempengaruhi keputusan konsumen antara lain: (1) Konsumen Individu, (2) Pengaruh Lingkungan, (3) Strategi Pemasaran. Sedangkan penelitian dari Desy (2016), brand image mempengaruhi keputusan pemilihan.

Menurut Setiadi (2010) mendefinisikan bahwa kelompok referensi melibatkan orang satu atau lebih yang dapat menjadikan pembandingan dalam membentuk tanggapan afeksi serta menyatakan perilaku seseorang. Adapun indikator dalam kelompok referensi yang digunakan dalam penelitian menurut Sumarwan (2004) sebagai berikut: (1) kelompok informal, (2) kelompok sekunder, (3) kelompok aspirasi, (3) kelompok disasosiasi.

Menurut Setiadi (2010) mendefinisikan bahwa keluarga merupakan kelompok dengan dua atau lebih orang yang mempunyai hubungan melalui darah, perkawinan atau adopsi maupun yang tinggal bersama. Adapun indikator dalam keluarga yang digunakan dalam penelitian menurut Setiadi (2010) sebagai berikut: (1) Keluarga Orientasi, (2) Keluarga Prokreasi.

Menurut Hurriyati (2010) motivasi merupakan kebutuhan yang memiliki tujuan untuk mengarahkan seseorang dalam mencari kepuasan. Adapun indikator dalam motivasi yang digunakan dalam penelitian menurut Setiadi (2010) sebagai berikut: (1) Pencapaian Prestasi (2) Kemungkinan Berkembang (3) Mutu Pendidikan

Menurut Swastha (2000) mendefinisikan bahwa lokasi adalah tempat yang mempunyai fungsi strategis karena dapat menentukan tercapainya tujuan dalam badan usaha. Adapun indikator dalam lokasi yang digunakan dalam penelitian menurut Fandy Tjiptono (2002) sebagai berikut: (1) Akses (2) Visibilitas (3) Lalu lintas (4) Lingkungan (5) Peraturan Pemerintah.

Menurut Laksana (2008) mendefinisikan harga merupakan sejumlah uang yang diperlukan untuk penukar berbagai kombinasi produk dan jasa. Adapun indikator dalam harga yang digunakan dalam penelitian menurut Laksana (2008) sebagai berikut: (1) Keterjangkauan Harga (2) Kesesuaian Harga dengan Kualitas (3) Kesesuaian Harga dengan Manfaat.

Menurut Alma (2003) mendefinisikan bahwa citra adalah perasaan yang ada pada publik mengenai lembaga. Adapun indikator dalam citra lembaga yang digunakan dalam penelitian menurut Alma (2003) sebagai berikut: (1) Mirror Image (2) Multiple image.

Menurut Setiadi (2010) mendefinisikan bahwa "Keputusan pembelian merupakan proses yang mengkombinasikan pengetahuan agar dapat mengevaluasi perilaku alternatif dan memilih salah satu diantaranya." Adapun indikator keputusan pembelian yang digunakan dalam penelitian ini menurut Kotler dan Keller (2009) sebagai berikut: (1) Pilihan Produk (2) metode pembayaran.

Menurut Kotler dan Keller (2009) ada 5 tahap proses keputusan pembelian antara lain: (1) Pengenalan Masalah (2) Pencarian Informasi (3) Evaluasi Alternatif (4) Keputusan Pembelian (5) Perilaku Pasca Pembelian. 
Hipotesis dalam penelitian ini diantaranya: 1) $\mathrm{H}_{1}$ : faktor yang mempengaruhi pemilihan Universitas pada siswa kelas XII SMA Negeri 22 Surabaya. 2) $\mathrm{H}_{2}$ : faktor yang mempunyai pengaruh paling dominan yang mempengaruhi pemilihan Universitas pada siswa kelas XII SMA Negeri 22 Surabaya

\section{METODE}

Jenis penelitian yang digunakan adalah pendekatan kuantitatif bersifat confirmatori. Populasi yang diketahui dalam penelitian ini yaitu 362 dari kelas XII SMA Negeri 22 Surabaya. Teknik sampling menggunakan proportional random sampling. Jadi jumlah sampel dalam penelitian ini sebanyak 190 siswa dari 362 responden/siswa.

Instrumen penelitian menggunakan angket dengan 5 skala likert karena mempunyai variabilitas respon lebih baik sehingga mampu mengungkap lebih maksimal perbedaan sikap responden (Widiyoko, 2014).

Dalam penelitian ini menggunakan analisis faktor dengan tujuan utama adalah mendefinisikan struktur suatu data matriks dan menganalisis struktur saling mempunyai hubungan (korelasi) antar jumlah besar variabel yaitu dengan cara mendefinisikan suatu kesamaan variabel dan disebut dengan faktor. Langkah-langkah dalam pelaksanaan analisis faktor menurut Malholtra (2005) sebagai beriku: (1) Memformulasikan Masalah (2) Membuat Matriks Korelasi (3) Menetapkan Metode Analisis (4) Menentukan Jumlah Faktor (5) Merotasi Faktor (6) Menafsirkan Faktor (7) Menentukan Model yang sesuai.

\section{HASIL DAN PEMBAHASAN}

Faktor yang digunakan untuk mengetahui keputusan pemilihan Universitas adalah kelompok referensi, citra lembaga, motivasi, keluarga, lokasi, dan harga. Responden dapat diidentifikasi melalui beberapa karakteristik antara lain jenis kelamin, jurusan, pekerjaan ayah, pekerjaan ibu, dan pendapatan keluarga.

\section{Analisis Hasil Penelitian}

Penelitian ini merumuskan 6 variabel yaitu kelompok referensi $\left(\mathrm{X}_{1}\right)$, keluarga $\left(\mathrm{X}_{2}\right)$, motivasi $\left(\mathrm{X}_{3}\right)$, lokasi $\left(\mathrm{X}_{4}\right)$, harga $\left(\mathrm{X}_{5}\right)$, citra lembaga $\left(\mathrm{X}_{6}\right)$ yang dikonfirmasi dari kajian teori analisis faktor yang mempengaruhi keputusan pembelian menuurut Kotler dan Keller. Proses analisis dilakukan berdasarkan matriks korelasi antar variabel, agar dapat analisiss faktor dilakukan maka variabel-variabel harus berkorelasi satu sama lainnya. Dilihat dari dua hal yaitu hasil Uji KaiserMayer-Olkin (KMO) dan nilai signifikansi. Tabel Uji Kaiser-Mayer-Olkin (KMO) sebagai berikut:

Tabel 1

KMO and Bartlett's Test

\begin{tabular}{lcc}
\hline \hline $\begin{array}{l}\text { Kaiser-Mayer-Olkin Measure of Sampling } \\
\text { Adequacy }\end{array}$ & .572 \\
$\begin{array}{lcc}\text { Bartlett's Test of } & \text { Approx. Chi-Square } & 310.745 \\
\text { Sphericity } & \text { Df } & 15 \\
& \text { Sig. } & .000\end{array}$
\end{tabular}

(sumber: data diolah, 2018) 
Berdasarkan tabel diatas dijelaskan bahwa hasil uji Kaiser-Mayer-Olkin (KMO) Measure of Sampling Adequacy sebesar 0,572 yang mempunyai arti ketepatan penggunaan analisis faktor dapat dipertanggungjawabkan, karena nilai Kaiser-Mayer-Olkin (KMO) diatas 0,5 dan nilai signifikansinya kurang dari 0,05 yang menunjukkan bahwa analisis tersebut tepat. Metode penelitian ini adalah metode Principal Component Analysis (PCA), metode ini menganjurkan apabila tujuan analisis faktor untuk memperkecil jumlah variabel asli, selanjutnya variabel/faktor disusun kembali menurut korelasinya dan progrm SPSS 16.0 for Windows akan menentukan jumlah faktor yang diperlukan untuk mewakili data.

Setelah menentukan dengan menggunakan metode analisis yaitu metode Principal Component Analysis (PCA), selanjutnya ditentukan jumlah faktor yang dianalisis. Setiap faktor mempunyai nilai keragaman data dari variabel asal (keputusan pemilihan), sehingga total variance explained menjadi output dapat menjelaskan tentang faktor yang terbentuk. Hasil dari Total Variance Explained sebagai berikut:

Tabel 2

Total Variance Explained

\begin{tabular}{|c|c|c|c|c|c|c|c|c|c|}
\hline \multirow[t]{2}{*}{$\begin{array}{l}\text { Compo } \\
\text { nent }\end{array}$} & \multicolumn{3}{|c|}{ Initial Eigenvalues } & \multicolumn{3}{|c|}{$\begin{array}{l}\text { Extraction Sums of Squared } \\
\text { Loadings }\end{array}$} & \multicolumn{3}{|c|}{$\begin{array}{l}\text { Rotation Sums of Squared } \\
\text { Loadings }\end{array}$} \\
\hline & Total & $\begin{array}{l}\% \text { of } \\
\text { Varianc } \\
\mathrm{e}\end{array}$ & Cumulative \% & Total & $\begin{array}{l}\% \text { of } \\
\text { Variance }\end{array}$ & $\begin{array}{l}\text { Cumula } \\
\text { tive }\end{array}$ & Total & $\begin{array}{l}\% \text { of } \\
\text { Varian } \\
\text { ce }\end{array}$ & $\begin{array}{l}\text { Cumul } \\
\text { ative } \\
\%\end{array}$ \\
\hline 1 & 2.682 & 44.701 & 44.701 & 2.682 & 44.701 & 44.701 & 1.939 & 32.315 & 32.315 \\
\hline 2 & 1.104 & 18.400 & 63.101 & 1.104 & 18.400 & 63.101 & 1.847 & 30.786 & 63.101 \\
\hline 3 & .752 & 12.541 & 75.642 & & & & & & \\
\hline 4 & .674 & 11.226 & 86.868 & & & & & & \\
\hline 5 & .566 & 9.436 & 96.304 & & & & & & \\
\hline 6 & .222 & 3.696 & 100.000 & & & & & & \\
\hline
\end{tabular}

Berdasarkan tabel di atas, bahwa hasil analisis faktor Total Variance Explained dapat dilihat faktor 1 sampai 6 yang terdapat dalam penelitian ini terdapat 2 komponen yang mempunyai nilai eigenvalue $>1$.

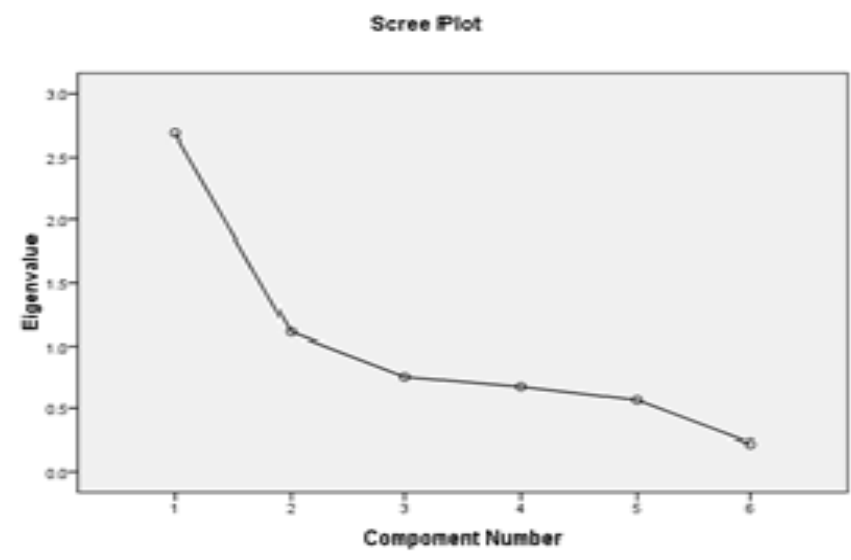

Gambar 1. Scree Plot 
Pada Scree Plot terlihat bahwa dari faktor 1 ke faktor 2 terjadi penurunan tajam. Untuk mengetahui indikator-indikator yang terbentuk, dapat dilihat dari isi masing-masing indikator. Isi daripada masing-masing indikator dapat diketahui dengan melihat nilai beban faktor pada tabel component matrix. Beban faktor menunjukkan semakin besar nilai beban faktor, maka semakin erat hubungan indikator tersebut pada komponen yang terbentuk.

Rotasi dilakukan untuk meminimalisasi data yang berulang antar indikator. Dengan rotasi faktor akan lebih mudah mengelompokkan faktor-faktor pada kedua komponen. Pengelompokkan tersebut dengan memperhatikan factors loadings yang nilainya diatas 0,5 .

Dalam penafsiran faktor diperoleh dari nilai loading factors yang terbesar dari faktor-faktor yang terbentuk dan telah terkelompokkan pada komponen.

Dalam penelitian dapat disimpulkan bahwa menggabungkan teknik penamaan faktor terhadap komponen yang terbentuk, yaitu menamai faktor baru secara subjektif dan diambil dari variabel yang memiliki nilai loading faktor tertinggi. Hasilnya sebagai berikut:

Tabel 4. Kelompok Faktor 1

\begin{tabular}{llllll}
\hline \hline Item & $\begin{array}{l}\text { Nilai } \\
\text { Loading } \\
\text { Faktor }\end{array}$ & $\begin{array}{l}\text { Nama } \\
\text { Faktor }\end{array}$ & $\begin{array}{l}\text { Nilai } \\
\text { Eigenvalues }\end{array}$ & $\begin{array}{l}\% \text { of } \\
\text { variance }\end{array} \%$ \\
\hline \hline $\mathrm{X}_{1.1}$ & .925 & & & \\
$\mathrm{X}_{1.5}$ & .925 & & & \\
$\mathrm{X}_{1.9}$ & .925 & & & \\
& & Kelompok & 14.441 & 42.474 & 42.474 \\
& & Referensi & & \\
$\mathrm{X}_{2.1}$ & .925 & & & \\
$\mathrm{X}_{2.2}$ & .925 & & & \\
$\mathrm{X}_{2.4}$ & .595 & & & \\
\hline
\end{tabular}

Dari hasil statistik faktor ini memiliki nilai eigenvalues terbesar yaitu 14.441, sehingga faktor kelompok referensi menjadi faktor pertama dalam keputusan pemilihan Universitas.

Tabel 5. Kelompok Faktor 2

\begin{tabular}{llllll}
\hline \hline Item & $\begin{array}{l}\text { Nilai } \\
\text { Loading } \\
\text { Faktor }\end{array}$ & $\begin{array}{l}\text { Nama } \\
\text { Faktor }\end{array}$ & $\begin{array}{l}\text { Nilai } \\
\text { Eigenvalues }\end{array}$ & $\begin{array}{l}\% \\
\text { variance }\end{array}$ \\
\hline \hline $\mathrm{X}_{6.3}$ & .821 & & & \\
$\mathrm{X}_{1.2}$ & .707 & & & \\
$\mathrm{X}_{1.4}$ & .707 & & & \\
$\mathrm{X}_{3.2}$ & .707 & & & \\
$\mathrm{X}_{4.7}$ & .707 & & & \\
$\mathrm{X}_{6.1}$ & .654 & & & \\
$\mathrm{X}_{3.3}$ & .626 & Citra & & & \\
$\mathrm{X}_{4.2}$ & .596 & Lembaga & 5.185 & & \\
$\mathrm{X}_{4.8}$ & .439 & & & & \\
\hline
\end{tabular}

Dari hasil statistik faktor ini memiliki nilai eigenvalues yaitu 5.185, sehingga faktor citra lembaga menjadi faktor kedua dalam keputusan pemilihan Universitas. 
Tabel 6. Kelompok Faktor 3

\begin{tabular}{llllll}
\hline \hline Item & $\begin{array}{l}\text { Nilai } \\
\text { Loading } \\
\text { Faktor }\end{array}$ & $\begin{array}{l}\text { Nama } \\
\text { Faktor }\end{array}$ & $\begin{array}{l}\text { Nilai } \\
\text { Eigenvalues }\end{array}$ & $\begin{array}{l}\% \text { of } \\
\text { variance }\end{array}$ & $\begin{array}{l}\text { Cumulative } \\
\%\end{array}$ \\
\hline $\mathrm{X}_{3.4}$ & .867 & & & & \\
$\mathrm{X}_{4.1}$ & .867 & & & & \\
$\mathrm{X}_{1.10}$ & .719 & & & & \\
$\mathrm{X}_{5.2}$ & .589 & & & & \\
$\mathrm{X}_{4.9}$ & .562 & Motivasi & 2.880 & 8.470 & 66.195 \\
$\mathrm{X}_{6.2}$ & .469 & & & & \\
\hline
\end{tabular}

Dari hasil statistik faktor ini memiliki nilai eigenvalues yaitu 2.880, sehingga faktor motivasi menjadi faktor ketiga dalam keputusan pemilihan Universitas.

Tabel 7. Kelompok Faktor 4

\begin{tabular}{llllll}
\hline \hline Item & $\begin{array}{l}\text { Nilai } \\
\text { Loading } \\
\text { Faktor }\end{array}$ & $\begin{array}{l}\text { Nama } \\
\text { Faktor }\end{array}$ & $\begin{array}{l}\text { Nilai } \\
\text { Eigenvalues }\end{array}$ & $\begin{array}{l}\% \text { of } \\
\text { variance }\end{array}$ & $\begin{array}{l}\text { Cumulative } \\
\%\end{array}$ \\
\hline $\mathrm{X}_{2.3}$ & .916 & & & & \\
$\mathrm{X}_{1.8}$ & .916 & & & & \\
$\mathrm{X}_{1.3}$ & .916 & Keluarga & 2.574 & 7.571 & 73.76 \\
\hline
\end{tabular}

Dari hasil statistik faktor ini memiliki nilai eigenvalues yaitu 2.574, sehingga faktor keluarga menjadi faktor keempat dalam keputusan pemilihan Universitas.

Tabel 8. Kelompok Faktor 5

\begin{tabular}{llllll}
\hline \hline Item & $\begin{array}{l}\text { Nilai } \\
\text { Loading } \\
\text { Faktor }\end{array}$ & Fama & Nilai & $\%$ of & Cumulative \\
& & & & \\
& & & & \\
& & & & \\
$\mathrm{X}_{6.1}$ & .853 & & & & \\
$\mathrm{X}_{3.1}$ & .853 & & & $6 / 004$ & 79.770 \\
$\mathrm{X}_{5.1}$ & .738 & & & & \\
$\mathrm{X}_{4.4}$ & .627 & Lokasi & 2.041 & & \\
\hline
\end{tabular}

Dari hasil statistik faktor ini memiliki nilai eigenvalues yaitu 2.041, sehingga faktor lokasi menjadi faktor kelima dalam keputusan pemilihan Universitas.

Tabel 9. Kelompok Faktor 6

\begin{tabular}{|c|c|c|c|c|c|}
\hline Item & $\begin{array}{l}\text { Nilai } \\
\text { Loading } \\
\text { Faktor }\end{array}$ & $\begin{array}{l}\text { Nama } \\
\text { Faktor }\end{array}$ & $\begin{array}{l}\text { Nilai } \\
\text { Eigenvalues }\end{array}$ & $\begin{array}{l}\% \text { of } \\
\text { variance }\end{array}$ & $\begin{array}{l}\text { Cumulative } \\
\%\end{array}$ \\
\hline 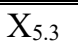 & 2.845 & & & & \\
\hline $\mathrm{X}_{3.5}$ & .775 & & & & \\
\hline $\mathrm{X}_{6.4}$ & .766 & & & & \\
\hline $\mathrm{X}_{3.6}$ & .701 & Harga & 1.372 & 4.035 & 83.804 \\
\hline
\end{tabular}


Dari hasil statistik faktor ini memiliki nilai eigenvalues yaitu 1.372, sehingga faktor harga menjadi faktor keenam dalam keputusan pemilihan Universitas.

Penentuan model yang tepat untuk mengetahui apakah model mampu menjelaskan dengan baik fenomena yang ada, perlu diuji ketepatannya. Dalam menguji ketepatan model analisis faktor dengan menggunakan metode PCA dapat dilakukan melihat besarnya presentase korelasi residual diatas $5 \%$.

\section{Pembahasan}

"Dalam penelitian dari 36 item telah dilakukan rotasi sehingga membentuk menjadi 6 faktor yaitu kelompok referensi, citra lembaga, motivasi, keluarga, lokasi, dan harga. Faktor-faktor ini berpengaruh terhadap keputusan pemilihan Universitas. Dalam 6 faktor semua mempunyai pengaruh. Berikut penjelasan berdasarkan besarnya nilai presentase varians:" Dalam hasil penelitian faktor kelompok referensi mempunyai pengaruh terhadap keputusan pemilihan Universitas. Hasil penelitian ini juga sesuai dengan teori Kotler dan Keller (2009) terdapat empat faktor utama yang mempengaruhi perilaku konsumen, salah satunya yaitu dari faktor sosial antara lain kelompok referensi.

"Kelompok referensi mempengaruhi siswa mengambil keputusan pemilihan Universitas karena siswa mempertimbangkan kelompok referensi berdasarkan kelompok informal, kelompok formal, kelompok sekunder, kelompok aspirasi, dan kelompok disasosiasi. Hasil menunjukkan kelompok referensi memiliki peran penting dalam mempengaruhi siswa untuk mengambil keputusan dalam memilih Universitas."

Dalam hasil penelitian faktor citra lembaga mempengaruhi keputusan pemilihan Universitas. Hasil penelitian ini juga sesuai dengan Elfira (2016) terdapat faktor yang mempengaruhi perilaku konsumen yaitu citra lembaga. Citra lembaga mempengaruhi siswa mengambil keputusan pemilihan Universitas karena siswa mempertimbangkan citra lembaga berdasarkan mirror image dan multiple image.

"Hasil menunjukkan bahwa citra lembaga memiliki peran penting dalam pemilihan Universitas. Citra lembaga dapat mendorong siswa untuk melakukan keputusan pemilihan, karena siswa akan mempertimbangkan seberapa bagus citra yang ditunjukkan kepada calon mahasiswa yang memilih Universitas tersebut."

Dalam hasil penelitian faktor motivasi mempengaruhi keputusan pemilihan Universitas. Hasil penelitian ini juga sesuai dengan teori Kotler dan Keller (2009) terdapat empat faktor utama yang mempengaruhi perilaku konsumen, salah satunya yaitu dari faktor psikologis antara lain motivasi. Motivasi mempengaruhi siswa dalam memilih Universitas karena siswa akan terdorong berdasarkan pencapaian prestasi, kemungkinan berkembang, dan mutu pendidikan.

Hasil menunjukkan bahwa motivasi memiliki peran yang penting dalam melakukan keputusan pemilihan, karena dengan adanya motivasi dari dalam diri maka siswa akan terdorong untuk melakukan pemilihan Universitas.

Dalam hasil penelitian, faktor keluarga mempengaruhi keputusan pemilihan Universitas. Hasil penelitian ini juga sesuai dengan teori Kotler dan Keller (2009) terdapat empat faktor utama yang mempengaruhi perilaku konsumen, salah satunya yaitu dari faktor sosial antara lain keluarga.

"Keluarga akan mempengaruhi siswa mengambil keputusan pemilihan Universitas karena siswa mempertimbangkan keluarga berdasarkan keluarga orientasi dan keluaga prokreasi.” 
Hasil menunjukkan bahwa keluarga sangat mempengaruhi dalam keputusan pemilihan, karena keluarga memberikan dorongan di setiap salah satu keluarganya akan melakukan keputusan terutama keputusan pemilihan Universitas. Dalam hasil penelitian faktor lokasi mempengaruhi keputusan pemilihan Universitas. Hasil penelitian ini juga sesuai dengan teori Henry Assael dalam Amirullah (2002) terdapat tiga faktor yang mempengaruhi keputusan konsumen salah satunya dari strategi pemasaran antara lain lokasi.

"Lokasi akan mempengaruhi siswa mengambil keputusan pemilihan Universitas karena siswa mempertimbangkan lokasi berdasarkan akses, visibilitas, lalu lintas, lingkungan, dan peraturan pemerintah." Hasil menunjukkan bahwa lokasi memiliki peran penting dalam mempengaruhi siswa memilih Universitas. Lokasi dapat menjadi pertimbangan siswa dalam memilih Universitas karena siswa melihat lokasi yang memiliki letak strategis.

Dalam hasil penelitian, faktor harga mempengaruhi keputusan pemilihan Universitas. Hasil penelitian ini sesuai dengan teori Henry Assael dalam Amirullah (2002) terdapat tiga faktor yang mempengaruhi keputusan konsumen salah satunya dari strategi pemasaran yaitu harga.

"Harga akan mempengaruhi siswa mengambil keputusan pemilihan Universitas karena siswa mempertimbangkan harga berdasarkan keterjangkauan harga, kesesuaian harga dengan kualitas, dan kesesuaian dengan manfaat jasa."

Hasil menunjukkan bahwa harga memiliki peran penting dalam mempengaruhi siswa memutuskan pemilihan. Harga merupakan faktor yang dapat mendorong siswa melakukan keputusan pemilihan Universitas.

Pada pembahasan analisis faktor maka dapat diketahui terdapat faktor yang paling dominan dalam keputusan pemilihan Universitas yaitu kelompok faktor pertama yaitu kelompok referensi karena siswa mendapatkan referensi dari banyak teman dan yang lain untuk memutuskan memilih Universitas. Kelompok faktor kedua yaitu citra lembaga, siswa memilih Universitas dengan cara melihat citra dari Universitas tersebut bagus atau tidak sehingga dengan citra dari Universitas siswa akan memutuskan pemilihan Universitas yang dipilih. Kelompok faktor ketiga yaitu motivasi, siswa mendapatkan dorongan dari dalam dirinya untuk memutuskan memilih Universitas yang dipilih.

"Kelompok faktor keempat yaitu keluarga, keluarga sangatlah penting memberikan saran, memotivasi salah satu keluarganya agar terdorong memilih Universitas yang dipilih sehingga salah satu keluarganya tidak merasa ragu melakukan keputusan pemilihan Universitas.”

Kelompok faktor kelima yaitu lokasi, lokasi merupakan peran penting dalam memilih Universitas yang dipilih, karena siswa dalam mengambil keputusan pemilihan harus melihat lokasi dari Universitas yang dipilih sehingga lokasi mempengaruhi keputusan pemilihan Universitas. Dan harga, harga memiliki peran penting dalam mengambil keputusan pemilihan Universitas karena harga juga faktor yang mendorong siswa dalam memilih Universitas.

\section{PENUTUP}

\section{Simpulan}

Hasil penelitian dan pembahasan dapat disimpulkan sebagai berikut: (1) Faktor kelompok referensi $\left(\mathrm{X}_{1}\right)$, keluarga $\left(\mathrm{X}_{2}\right)$, motivasi $\left(\mathrm{X}_{3}\right)$, lokasi $\left(\mathrm{X}_{4}\right)$, harga $\left(\mathrm{X}_{5}\right)$, dan citra lembaga $\left(\mathrm{X}_{6}\right)$ mempengaruhi keputusan pemilihan Universitas pada siswa kelas XII SMA Negeri 22 Surabaya. (2) Kelompok faktor pertama kelompok referensi, kedua citra lembaga, ketiga motivasi, keempat keluarga, kelima lokasi, dan keenam harga yang mempunyai pengaruh paling dominan terhadap 
keputusan pemilihan Universitas pada siswa kelas XII SMA Negeri 22 Surabaya.

\section{Saran}

Berdasarkan hasil penelitian, adapun saran sebagai berikut: (1) Berdasarkan hasil penelitian kelompok referensi mempengaruhi keputusan pemilihan Universitas, maka diharapkan guru dari SMA Negeri 22 Surabaya harus lebih memberikan masukan informasi mengenai Universitas agar siswa tidak ragu dalam memilih Universitas yang mereka pilih. (2) Berdasarkan hasil penelitian dari faktor harga, maka diharapkan sekolah lebih sering mendatangkan alumni dari sekolah yang berkuliah di Universitas tersebut sehingga siswa mengetahui kualitas jasa yang diberikan di Universitas tersebut.

\section{DAFTAR PUSTAKA}

Alma, Buchari. 2003. Strategi Pemasaran Jasa Pendidikan. (5th ed). Bandung: Alfabeta

Amirullah. 2002. Perilaku Konsumen. Edisi Pertama. Cetakan Pertama. Yogyakarta: Graha Ilmu.

Artini, I Dewa Ayu Juli, I Ketut Kirya, dan I Wayan Suwendra. 2014. "Faktor-Faktor yang Mempengaruhi Keputusan Mahasiswa dalam Memilih Jurusan di Fakultas Ekonomi dan Bisnis (FEB) Universitas Pendidikan Ganesha (UNDIKSHA) sebagai Tempat Kuliah”. EJournal Bisma Universitas Pendidikan Ganesha. Vol.2.

Desy, Elfira. 2016. "Pengaruh Brand Image,Lokasi dan Fasilitas Terhadap Keputusan Mahasiswa Memilih Universitas Pancabudi (Studi Kasus Mahasiswa Fakultas Ekonomi)”. Jurnal Ilmiah "Dunia Ilmu”. Vol.2 No.1.

Hurriyati, Ratih. 2010. “Bauran Pemasaran dan Loyalitas Konsumen”. Bandung: Alfabeta.

Kompas. 2011. Memilih Perguruan Tinggi dan Masa Depan. http://edukasi.kompas.com/read/2011/05/02/14061246/Memilih.Perguruan.Tinggi.dan.Mas a.Depan. (Online). Diakses 20 Februari 2017.

Kotler, Philip dan Kevin Lane Keller. 2009. Manajemen Pemasaran. Edisi 13. Jilid 1. Jakarta:Erlangga

Laksana, F. 2008. Manajemen Pemasaran (1 ${ }^{\text {st }}$ ed). Yogyakarta : Graha Ilmu

Setiadi, Nugroho. 2010. Perilaku Konsumen. Cetakan Keempat. Jakarta: Kencana Prenada Media Group.

Sumarwan, Ujang. 2004. Perilaku Konsumen: Teori dan Penerapannnya dalam Pemasaran. Bogor: Ghalia Indonesia.

Tjiptono, Fandy. 2002. Strategi Pemasaran. Yogyakarta : Andi

Widoyoko, Eko Putro. 2014. Teknik Penyusunan Instrumen Penelitian. Cetakan Ketiga. Yogyakarta:Pustaka Pelajar.

Malholtra, Naresh. 2005. Metode Riset untuk Bisnis dan Ekonomi. Jakarta: PT.Indeks Kelompok Gramedia. 